\title{
RIBEIRA EM FOCO: CONCURSO BID URBANLAB BRASIL/NATAL - PERSPECTIVAS UNIVERSITÁRIAS
}

\author{
RIBEIRA EN FOCO: CONCURSO BID URBANLAB BRASIL/NATAL - PERSPECTIVAS DE LA \\ UNIVERSIDAD
}

RIBEIRA IN FOCUS: IDB URBANLAB BRAZILCONTEST/NATAL - UNIVERSITY PERSPECTIVES

\section{SILVA, MARIA FLORESIA PESSOA DE SOUZA E}

Arquiteta e Urbanista, Doutora, Secretaria Adjunta de Planejamento Urbanístico e Gestão Ambiental da Secretaria de Meio Ambiente e Urbanismo de Natal. mfpss2007@hotmail.com

SANTOS, KARITANA MARIA DE SOUZA

Arquiteta e Urbanista, Mestre, Arquiteta da Secretaria de Meio Ambiente e Urbanismo de Natal. karitanasouza@hotmail.com

\section{COBBE, ANDRÉ LUIS CERQUEIRA DE OLIVEIRA}

Arquiteto e Urbanista, Especialista, Consultor do Banco Interamericano de Desenvolvimento (BID). andre.luis.cobbe@gmail.com

\section{INTRODUÇÃO}

O BID UrbanLab é um concurso universitário, organizado pelo Banco Interamericano de Desenvolvimento (BID), destinado a buscar soluções criativas e ideias inovadoras para os problemas urbanos da América Latina e do Caribe (ALC), em parceria com estudantes, professores universitários e jovens profissionais. Os seus objetivos são: atuar como incubadora de jovens talentos em temas urbanísticos, a partir de uma rede de trabalho com universidades; promover um espaço participativo para o questionamento dos paradigmas atuais, que orientam as práticas em projetos urbanos; bem como introduzir no mercado de trabalho jovens que se interessam em atuar nesta área.

As duas primeiras edições tiveram alcance internacional. A primeira, em 2015, abordou temas urbanos no bairro de Curundú, no Panamá. Em 2016, a cidade de Santa Marta, Colômbia, sediou o concurso com propostas para o bairro de Pescaíto. No ano de 2017, o BID pôde atestar o sucesso de sua iniciativa e, diante dele, lançou a terceira edição, em parceria com a Província de Mendoza, na Argentina. Motivou-se também a lançar, concomitantemente com a terceira edição internacional, a primeira edição de caráter estritamente nacional, no Brasil, como forma de incentivar a participação das universidades brasileiras que estiveram ausentes nas edições anteriores. Assim, lançou-se em 2017 o BID UrbanLab Brasil, 1a Edição, e com ele, a escolha do bairro Ribeira, abrangendo um polígono de intervenção com caráter histórico de Natal, berço da capital do Rio Grande do Norte. Nessa edição, o BID contou com a participação da Prefeitura Municipal do Natal, que disponibilizou informações e supervisão; e o apoio da Caixa Econômica Federal (CAIXA) e do Ministério as Cidades.

O concurso BID UrbanLab Brasil 1a Edição teve um amplo alcance, com a participação de quarenta equipes, de trinta e uma universidades, originárias de dezesseis cidades do país. A Universidade Federal do Rio Grande do Norte (UFRN) destacou-se, classificando-se com seis projetos, dentre os vinte projetos semifinalistas, quais sejam: Ribeira Conectada; Cidade Nascente; (+) Ribeira; Olhos da Ribeira; Trilhos da Ribeira; e Ribeira, Foz da Cidade. Ao final, foram laureadas duas equipes da UFRN, a equipe Ribeira: Foz da Cidade, com menção honrosa e a equipe Olhos da Ribeira, vencedora do concurso. 


\section{SELEÇÃO DE NATAL COMO CIDADE SEDE DO CONCURSO}

Natal, Rio Grande do Norte (RN), foi uma das cidades selecionadas para participar da fase de manifestação de interesse do concurso BID UrbanLab Brasil 1a Edição, num convite precedido por estudos e discussões técnicas e guiado por critérios estabelecidos pelo Banco Interamericano de Desenvolvimento (BID). Em 16 de março de 2017, foi solicitada à Secretaria de Meio Ambiente e Urbanismo (SEMURB) a indicação, em prazo máximo de 4 dias, de até três áreas de intervenção projetual no município. Para cada área deveriam ser realizadas propostas técnicas com memorial descritivo, mapas georreferenciados e ilustrativos, identificação das características e principais problemas a serem avaliados pelas universidades postulantes ao certame.

Como regras para seleção das áreas, o BID estabeleceu que as mesmas deveriam considerar: i) um tema urbano estratégico e de interesse regional; ii) a disponibilidade de informação técnica sobre o polígono de intervenção com área entre 15 a 20 ha; iii) uma pertinente justificativa sobre a carência da área por projetos; iv) a inserção da área no zoneamento do Plano Diretor; v) os suficientes levantamentos para embasamento para o devido desenvolvimento de projeto urbano (dados topográficos, socioeconômicos, ambientais, fundiários, demográficos, normativos e legais); vi) uma polígono com potencial de gerar um projeto integrado e intersetorial, abrangendo aspectos ligados à habitação, ao saneamento, à mobilidade, ao turismo, e que possa promover a revitalização e a requalificação social, ambiental e urbana da área. A Prefeitura do Natal, através da SEMURB, confirmou a candidatura da cidade e indicou três possíveis áreas de intervenção situadas nos bairros da Ribeira, Redinha e Praia do Meio / Santos Reis.

Para eleger a cidade sede do concurso, foi realizado um amplo estudo técnico pela equipe do BID que iniciou com a criação de uma matriz com dados relevantes sobre os municípios brasileiros com população entre 100 mil e 2 milhões de habitantes que apresentassem alta taxa de crescimento populacional, economia crescente e que começassem a apresentar problemas urbanos semelhantes aos das grandes cidades, decorrentes de sua rápida expansão. Estes municípios são considerados Cidades Emergentes, pelos critérios do BID. A partir dessa matriz, foram ranqueados 302 municípios, sendo destacados os 50 primeiros colocados, que foram submetidos a novos estudos com a participação da CAIXA e do Ministério das Cidades. Tais estudos, resultaram em novo ranking que considerou cada um dos municípios a partir de sua relevância no cenário nacional, sobretudo, nos aspectos socioeconômicos e turísticos. Destacaram-se três cidades - Maceió (AL), Olinda (PE) e Natal (RN) -, que foram convidadas a participar de qualificação com o objetivo de certificar e capacitar os seus quadros técnicos para o apoio à realização do concurso. Natal foi o município que atendeu a todas as solicitações, observando o prazo previsto e apresentando uma base de informações com excelente qualidade, garantindo a sua qualificação final para sediar o UrbanLab Brasil 1a Edição.

A área da cidade escolhida foi o bairro Ribeira, com caráter histórico e que se encontra em estado de deterioração urbana, letargia econômica e apresenta problemas socioambientais importantes. Foi estabelecido um recorte com aproximadamente 20 hectares a ser contemplado pelo concurso. A escolha da poligonal justifica-se pela premente demanda por soluções com vistas à reabilitação do centro histórico de Natal, considerando o grande número de imóveis desocupados (inclusive, alguns em ruínas), apresentandose um adequado locus para exercícios e experimentações.

As questões latentes do bairro Ribeira mostraram-se estratégicas para integrar projetos urbanos que apontem caminhos para a recuperação de uma área que apresenta um evidente processo de degradação física, requerendo ações que englobem a preservação do sítio histórico da cidade e a promoção de desenvolvimento social e econômico do bairro. Para o alcance dos objetivos propostos, a SEMURB indicou algumas diretrizes que deveriam ser consideradas pelas propostas do concurso: (i) revisão do sistema viário da área, de modo a aperfeiçoar a mobilidade (pedestres, ciclistas, transporte público e veículos privados) e criação de bolsões de estacionamento; (ii) incentivo à diversificação dos diferentes usos do solo na área, priorizando: residencial, institucional, turístico, cultural e de lazer; I; (iii) recuperação e reuso de imóveis em ruínas; (iv) ampliação da cobertura vegetal; (v) proposição de usos que promovam a integração da comunidade da AEIS Maruim, recém instalada no Residencial São Pedro através do Programa Minha Casa Minha Vida, com a dinâmica da área; (vi) previsão de espaços para a promoção de atividades culturais; (vii) utilização do transporte fluvial, tanto para fins turísticos como para alternativa de transporte público; e (viii) valorização do visual cênicopaisagístico do Rio Potengi. 


\section{REGRAS DO CONCURSO E JULGAMENTOS DAS PROPOSTAS}

As regras do BID UrbanLab Brasil 1a Edição, estabeleciam que o concurso seria dirigido a estudantes de graduação que estivessem cursando os dois últimos anos do curso universitário (cursos com mínimo de quatro e o máximo de cinco anos), estudantes de pós-graduação em qualquer especialidade e professores universitários, na função de supervisores. As equipes poderiam ter em sua composição (dentro do limite de membros) até dois jovens profissionais. Todos os participantes deveriam formar, obrigatoriamente, equipes multidisciplinares de no mínimo quatro e no máximo seis membros, que atendessem às seguintes condições: (i) estarem matriculados como estudantes (graduação ou pós-graduação), em uma universidade brasileira; (ii) os docentes supervisores deveriam estar no exercício do cargo no momento da inscrição no concurso; (iii) os jovens profissionais deveriam estar formados há no máximo três anos; (iv) os membros da equipe, excetuando-se o docente supervisor, deveriam ter, no máximo, trinta e cinco anos de idade no momento da inscrição; (v) os jovens profissionais deveriam ter estudado em universidade brasileira.

Foram admitidos brasileiros, naturalizados ou estrangeiros (naturais de algum país membro do BID), desde que estivessem matriculados ou estudando em alguma universidade brasileira. A apresentação das propostas urbanísticas deveria ser enviada no formato de painel gráfico tamanho $A 1$, com conteúdo livre, porém com informações suficientes para o perfeito entendimento da proposta, bem como seguir parâmetros específicos, dispostos na página WEB UrbanLab Brasil. Para receber inscrições e propostas, em todas a fases do concurso, disponibilizou-se acesso às equipes postulantes à plataforma da WEB denominada Younoodle.

Para avaliar as proposições, indicou-se um corpo de jurados internacional que contou com representantes especialistas do BID, Prefeito Municipal, Secretária do Meio Ambiente e Urbanismo (SEMURB) do Natal e Secretária Adjunta de Planejamento Urbanístico e Gestão Ambiental (SAIPUGA/SEMURB). Três personalidades brasileiras com destaque em matérias afins ao concurso: Dr. Philip Yang; Arquiteto Paulo Casé e Clarisse da Cunha Linke, diretora do Instituto de Políticas e Transporte \& Desenvolvimento - ITDP, um representante da CAIXA e um do Ministério das Cidades, somando-se um corpo de jurados com 41 componentes.

O processo de avaliação, até a destinação da láurea, ensejou três fases: a fase de candidatura e apresentação das propostas, a fase de seleção de vinte propostas semifinalistas, por um comitê interno do BID, para, então, serem qualificadas três equipes para a fase final, correspondente à apreciação pelo júri internacional. Depois dessas três fases, as três equipes finalistas apresentariam presencialmente o seu trabalho ao júri que votou, em seguida, através de sistema eletrônico, obtendo-se prontamente o resultado. Destaca-se que a premiação do UrbanLab Brasil 1a Edição teve sua cerimônia oferecida na sede do BID em Washington (DC), EUA, sucedida por recepção oferecida pelo Embaixador do Brasil Sérgio Amaral, na Embaixada do Brasil naquele país. O BID ofereceu, como parte do prêmio, a estada a três representantes da equipe vencedora e ao docente supervisor; as estatuetas e os diplomas para os três primeiros colocados; além de cinco diplomas de menção honrosa para outras equipes classificadas. Adicionalmente, a equipe vencedora recebeu a quantia de US\$ 5.000 (cinco mil dólares) e os oito trabalhos selecionados foram expostos no saguão principal da sede do BID em Washington, D.C. A fase de coroamento do concurso, no entanto, foi quando, de volta ao Brasil, a equipe vencedora pôde validar e adaptar a sua proposta urbana, trabalhando, por um mês, em Natal (RN), junto a técnicos da SEMURB e especialistas do BID.

A equipe vencedora do UrbanLab Brasil 1a Edição destacou-se em Washington (DC), apresentando o trabalho intitulado "Olhos da Ribeira", bastante reconhecido pelos jurados. Vinculada à Universidade Federal do Rio Grande do Norte (UFRN), foi constituída pelos estudantes Marcela Lorena Scheer, Dmetryus Targino de Souza, Nicholas Saraiva Martino e Mariah Oliveira Holder da Silva e pela professora orientadora, Dr. $^{\text {Ruth }}$ Maria da Costa Ataíde, integrante do corpo docente do Departamento de Arquitetura da UFRN.

A equipe, além de superar todos os desafios impostos pelas regras do concurso, concorreu, conforme mencionado, com quarenta equipes de trinta e uma instituições universitárias, sediadas em dezesseis cidades de todo o país. O diferencial trazido pela proposta vencedora foi a aplicação de tecnologia, propondo uma rede social de apoio e monitoramento às ações sugeridas para a área de intervenção, privilegiando a comunidade local e estimulando o sentimento de pertencimento das pessoas ao lugar. Essa inovação buscou fortalecer a participação cidadã em prol da preservação dos marcos patrimoniais e afetivos da área e estimular a apropriação dos espaços públicos pelos locais, revelando a Ribeira aos olhos da cidade. Como resultado, o trabalho da equipe foi finalizado no formato de um MasterPlan preliminar que ficará como legado para a municipalidade. 
Figura 01: Foto da equipe vencedora da UFRN recebendo prêmio em Washington

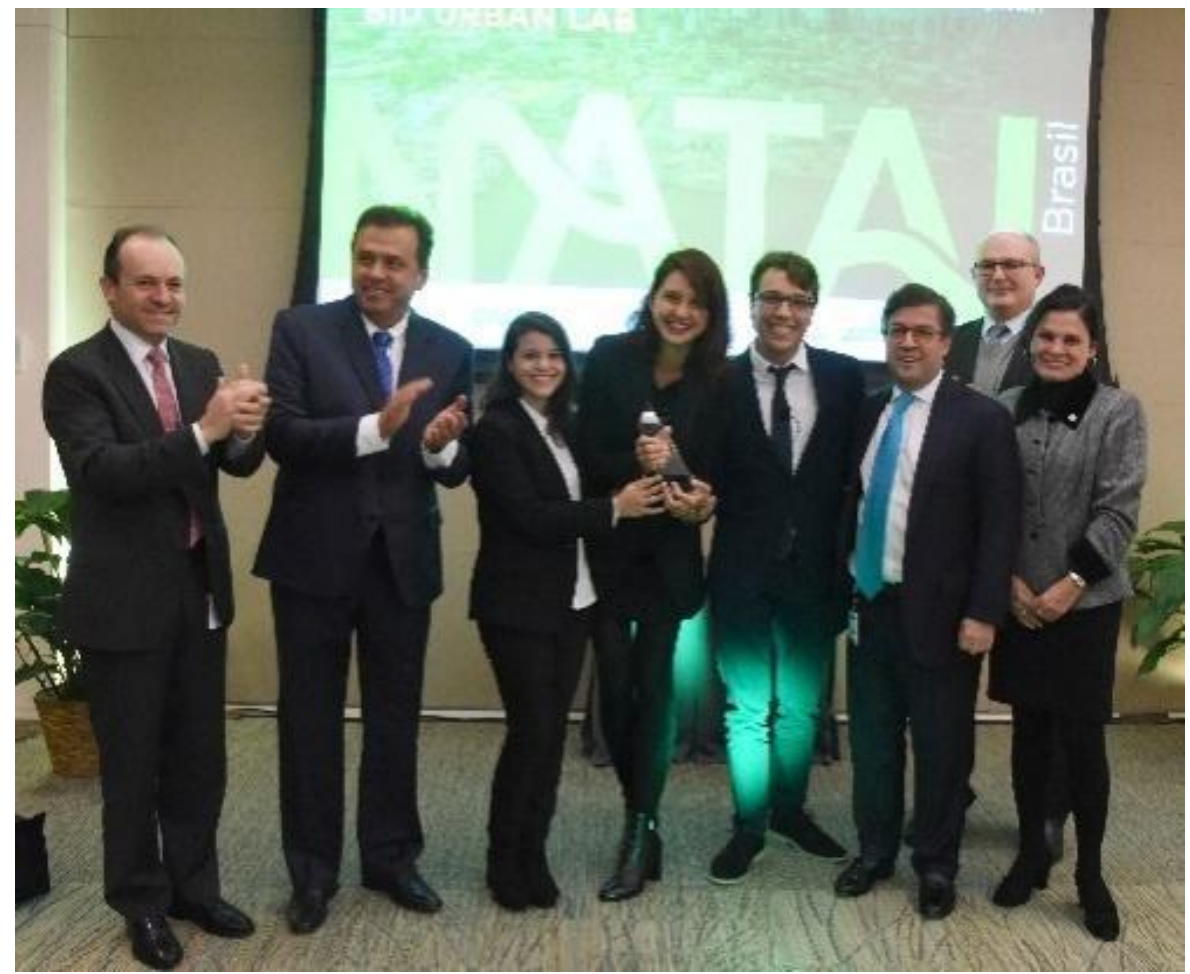

Fonte: BID (2017)

\section{RESGATE HISTÓRICO DAS INTERVENÇÕES NA RIBEIRA}

No final do século $X X$, quando as políticas progressistas declinaram em função do neoliberalismo, internacionalização da economia e da competitividade entre cidades (Harvey, 1992, 1996), projetos de reestruturação urbana passaram a ocorrer, em grande parte, como fruto de aliança entre capitais públicos e privados. Os estudos de Neil Smith (1996) observaram que os processos de reestruturação passaram a se dar de diferentes maneiras se adequando a cada espaço geográfico onde ocorriam. Identificaram a existência de ciclos de desvalorização, os quais, por vezes, induziam à renovação urbana; por outras, não se completavam a ponto de gerar o interesse do capital em investir nas áreas degradadas, o que chamou de "renda diferencial" (rent gap). O autor explica que o reinvestimento em uma área exige que a mesma decline, ou se valorize, até atingir um determinado ponto, quando se torna economicamente viável para os empreendedores reinvestirem ali. Entre os possíveis investimentos, aqueles em bens imóveis assumem especial importância pela margem de lucro que possibilitam ${ }^{1}$.

A Ribeira, desde 1980, vem vivenciando fases de projetos e investimentos, contudo, sem atingir uma real transformação e, até então, sem ter conseguido se desvencilhar de uma imagem de decadência. Cada nova tentativa, geralmente pouco ou não articulada entre elas, utilizou uma nova terminologia (recuperação, revitalização, reabilitação) para indicar a almejada renovação e busca por uma atratividade perdida. No entanto, observa-se que as ideias, muitas vezes, se repetiram, moldando cenários com projetos de maior ou menor envergadura, de acordo com as cifras previstas para investimento. Na prática, cada um dos diversos projetos sinalizaram um tempo curto de valorização e, às vezes, alguma prosperidade sem, contudo, alavancar uma dinâmica de maior permanência.

Na referida década, destacamos iniciativas importantes como a recuperação do Teatro Alberto Maranhão e um novo zoneamento apresentado no Plano Diretor de 1984 (Lei $N^{\circ} 3.175 / 1984$ ), contendo as zonas de proteção da área portuária e do sítio histórico. Dessas iniciativas derivaram-se as leis específicas para a Zona Especial de Preservação Histórica (Lei № 3.942/1990) e a Zona Especial Portuária (Lei № 4.069/1992). $\mathrm{Na}$ sequência, após a edição de um Plano Diretor baseado nos postulados da Reforma Urbana (Lei Complementar 07/1994), veio a primeira Lei de Operação Urbana Ribeira (Lei № 4.932/1997). 
Na década de 1990, o Seminário Ribeira Velha de Guerra discutiu o tema e formulou propostas que subsidiaram o novo Plano Diretor de 1994. Um novo Projeto denominado Viva Ribeira, executou um projeto: Fachadas da Rua Chile, em 1996, realizando a pintura de 45 fachadas dessa via, com o objetivo de chamar atenção da população para o processo de abandono que já se instalava na área.

Desde os anos 1990, alguns poucos empreendedores e ações culturais persistem, contribuindo com a preservação de alguma vitalidade na Ribeira. Entretanto, em grande parte, os imóveis no bairro estão fechados e abandonados. Mais recentemente, observa-se, inclusive, que diversas instituições públicas, que movimentam o fluxo de pessoas na área, começam a mudar para outros setores da cidade, aprofundando o cenário de abandono e degradação.

Em 2000, um novo setor responsável por cuidar do Patrimônio Histórico foi criado, vinculado à Secretaria de Meio Ambiente e urbanismo (SEMURB), numa clara demonstração da valorização das questões relativas ao patrimônio histórico. No mesmo período, um novo projeto para a área foi anunciado (Projeto Ribeira: Reabilitação Urbana), conjuntamente com a aprovação da Lei de Tombamento Municipal (Lei № 5.191/2000).

O Projeto Rehabitar, publicado em julho de 2007, surgiu no bojo das mudanças pautadas pela nova Constituição de 1988, o Estatuto das Cidades e a Medida Provisória 2.220, sendo formulado a partir de um convênio de cooperação técnica entre Prefeitura Municipal de Natal (através da SEMURB), Programa Cidade Brasil e Caixa Econômica Federal. Esse trabalho, realizado pelos técnicos das instituições envolvidas e consultoria de experts franceses, resultou em estudos e proposições de ações de intervenções legais, arquitetônicas e urbanísticas, pautadas na sustentabilidade financeira, capazes de atrair novos residentes para a área, e especialmente, causar impacto social positivo nos poucos habitantes que permaneciam no local.

Concomitantemente, outro trabalho estava sendo desenvolvido também pela Prefeitura Municipal de Natal, na mesma área, denominado de Plano de Reabilitação de Áreas Urbanas Centrais - Ribeira, resultado de um Programa do Governo Federal, através do Ministério das Cidades, o qual também contava com apoio da Caixa Econômica Federal, e foi conduzido pela Secretaria de Planejamento, Orçamento e Finanças. De maior amplitude, este plano foi elaborado pela UFRN e sua publicação ocorreu em 2008, no mesmo ano em que foi publicado o livro do Rehabitar. Uma clara demonstração de duplicidade de esforços, de um planejamento não integrado. Estes trabalhos resultaram em duas publicações com diagnósticos e propostas com qualidade técnica indiscutível, viabilidade e sustentabilidade de proposições, mas culminaram, mais uma vez, em poucos resultados práticos.

A nova edição da Lei de Operação Urbana Ribeira, em 2007 (Lei Nº79/2007), se mostrou mais efetiva na condição de atrair novos moradores para a área. Como resultado dessa legislação, deu-se a possibilidade de construir novos prédios verticalizados que atraíram mais de 1300 novos moradores. No entanto, eles ocorreram no entorno, nos limites do bairro, não conseguindo atingir o objetivo primeiro de recuperação do sítio histórico. Na prática, os novos prédios que ocuparam os arredores da área de maior valor histórico, foram beneficiados com a flexibilização de índices urbanísticos, entretanto, as contrapartidas exigidas não foram capazes de gerar a transformação almejada ou eliminar o cenário de degradação da área.

Um problema recorrente resultante das tentativas de reabilitação de áreas em declínio econômico tem sido a gentrificação. Os sítios históricos vivenciam ciclos de degradação e investimentos dentro de uma lógica de mercado, onde o uso residencial tende a atrair novos moradores, com perfis diversos dos que, cotidianamente, vivenciam esse processo de deterioração, ocasionando uma substituição da população habitual, por uma população de maior poder aquisitivo. No caso da Ribeira, os novos moradores ocuparam, em grande parte, terrenos vazios, antigos armazéns e antigas indústrias já abandonadas, nas bordas do bairro. Se houve a gentrificação, esta se deu de forma tão limitada quanto foi o alcance real dos projetos propostos.

Um evento importante ocorrido em 2010 foi o tombamento do conjunto arquitetônico, urbanístico e paisagístico da cidade de Natal pelo IPHAN, através de normativa específica que gerou novas exigências aos investidores e proprietários da área, impedindo a não descaracterização das reformas e impondo maior rigor aos projetos.

Em 2013, uma reunião de trabalho entre SEMURB, CODERN, SECTUR e IPHAN sobre o uso do Largo da Rua Chile como estacionamento do novo terminal de Passageiros da CODERN, deu início à formação de um 
grupo técnico, com integrantes das três esferas de poder, que congregou técnicos que estavam diretamente envolvidos com as questões cotidianas da área, possibilitando a atualização do diagnóstico dos problemas, e especialmente, dos projetos em execução, em elaboração ou anunciados para a área da Ribeira e seu entorno. Esse grupo se consolidou através de uma portaria municipal com o nome COOPERE. Foi realizado o seminário Ribeira em Foco, em julho de 2015, que contou com a participação de mais de 100 pessoas interessadas em debater as questões dessa área. Os dados sobre as condições da infraestrutura instalada, até então anunciada como excelente, mostrou que já carecia de investimentos importantes, especialmente nos itens de drenagem e iluminação pública, assim como apontou a violência urbana como o maior entre seus problemas.

Uma tabela somando mais de 800 milhões de investimentos na área e entorno (Figura 02), e um mapa (Figura 03) localizando mais de trinta grandes projetos, previstos para serem executados, mostravam que a Ribeira não estava abandonada. Alguns destes projetos, hoje, já se concretizaram: O terminal de Passageiros da CODERN (que anuncia iniciar seu funcionamento em agosto deste ano também como espaço de eventos), o condomínio Parque São Pedro (remoção da Favela do Maruim), o Centro Acadêmico do IFRN, os novos VLT's da CBTU já entraram em operação, a reforma do mercado das Rocas, a nova iluminação da Rua Duque de Caxias, são alguns entre os citados. O seminário finalizou deixando evidente que a Ribeira carece especialmente de propostas que articulem os projetos existentes à oferta de financiamento aos pequenos investidores e proprietários e, também, que seja instaurado um núcleo gestor que conte com os representantes das esferas governamentais e com os representantes dos variados segmentos da sociedade, com especial participação da população residente.

Figura 02: Valores dos investimentos previstos para a Ribeira e entorno em 2015

\begin{tabular}{|c|c|}
\hline \multicolumn{2}{|l|}{ GOVERNO FEDERAL } \\
\hline PAC CIDADES HISTÓRICAS (PMN, GOV RN, IPHAN E UFRN) & $\mathrm{R} \$ 43.478 .414,26$ \\
\hline PAC MOBILIDADE URBANA (CBTU) & $\mathrm{R} \$ 316.000 .000,00$ \\
\hline MINHA CASA MINHA VIDA - COMUNIDADE DO MARUIM (PMN/SEHARPE) & $\mathrm{R} \$ 12.200 .000,00$ \\
\hline MINISTÉRIO DA PESCA-TERMINAL PESQUEIRO (CODERN) & $\mathrm{R} \$ 37.000 .000,00$ \\
\hline CODERN - TERMINAL DE PASSAGEIROS & $\mathrm{R} \$ 75.000 .000,00$ \\
\hline CODERN - BERÇO 4 , ATRACADOURO PARA PESCA, PROTEÇÃO PONTE & $\mathrm{R} \$ 276.000 .000,00$ \\
\hline MINISTÉRIO DA EDUCAÇÃO - IFRN ROCAS & $\mathrm{R} \$ 6.000 .000,00$ \\
\hline TOTAL: & $R \$ 765.678 .414,26$ \\
\hline \multicolumn{2}{|l|}{ GOVERNO DO ESTADO DO RN } \\
\hline REABILITAÇÃO DO CENTRO HISTÓRICO DE NATAL & $\mathrm{R} \$ 2.228 .000,00$ \\
\hline MUSEU DA RAMPA & $\mathrm{R} \$ 8.000 .000,00$ \\
\hline IMPLANTAÇÃO DO COMPLEXO "RAMPA" & RS $7.222 .417,22$ \\
\hline TOTAL: & $R \$ 17.450 .417,22$ \\
\hline \multicolumn{2}{|l|}{ PREFEITURA MUNICIPAL DE NATAL } \\
\hline URBANIZAÇÃO DA COMUNIDADE MARUIM & $\mathrm{R} \$ 4.271 .294,28$ \\
\hline MERCADO DAS ROCAS & $\mathrm{R} \$ 4.500 .000,00$ \\
\hline TOTAL: & $\mathrm{R} \$ \mathbf{8 . 7 7 1 . 2 9 4 , 2 8}$ \\
\hline TOTAL GERAL DOS INVESTIMENTOS NA RIBEIRA E ENTORNO & $\mathrm{R} \$ 791.900 .125,76$ \\
\hline
\end{tabular}

Fonte: SEMURB (2015) 
Figura 03: Mapa dos projetos previstos para a Ribeira e entorno em 2015

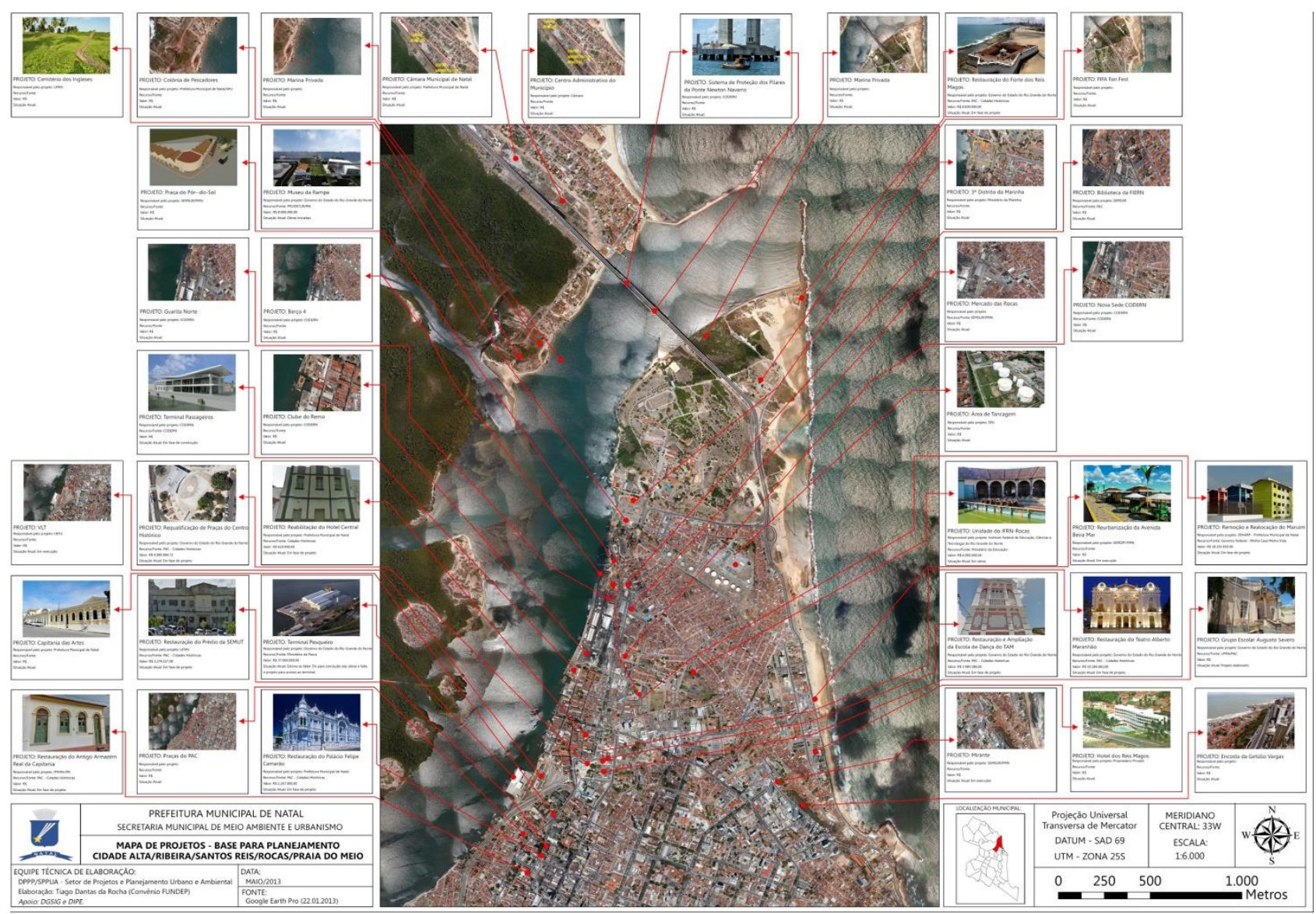

Fonte: SEMURB (2015)

Uma terceira Lei de Operação Urbana, em elaboração na SEMURB, intenciona ampliar o perímetro de intervenção e incluir toda a área do Sítio Histórico, em substituição à lei que se extinguiu em janeiro de 2013. Entre as ideias discutidas no Evento First IEEE International Summer School on Smart Cities ${ }^{2}$ em parceria com Instituto Metrópole Digital da UFRN, idealiza-se a criação de um centro de apoio às start ups de cunho social e cultural, com o título de Ribeira Living Lab, o qual começa recentemente a ser viabilizado através da doação de um prédio da Secretaria Patrimônio da União para tal finalidade. Outras propostas inovadoras indicam aplicativos para celulares que criem agendas culturais e permitam integração trazendo novos olhares para a área.

Observa-se que novas iniciativas privadas continuam a ocorrer de forma tímida, como a recente instalação da Galeria de Arte B-612, de propriedade do Sr. Anchieta Miranda, que enche os olhos e coração daqueles que descobrem, no meio daquele aparente abandono, a riqueza da arte potiguar, somando-se a outras iniciativas que resistem bravamente, como a Casa da Ribeira, alguns bares, o ateliê do artista Flávio Freitas e o café salão da cabeleireira Nalva Melo, que se tornaram pontos de referência da Ribeira.

O concurso BID UrbanLab Brasil 1ª Edição chegou, assim, oportunamente, organizando uma proposta que poderá agregar e ser complementada com outras novas ideias. Servindo de ponto de partida para criar um projeto urbano que servirá de âncora para a nova Lei de Operação Urbana que se pretende conduzir.

\section{PRINCIPAIS RESULTADOS E ENCAMINHAMENTOS}

O projeto ganhador do concurso denominado Olhos da Ribeira foi apresentado, em Natal, em um evento especial denominado Seminário Ribeira em Foco II: Concurso BID UrbanLab Natal/Brasil, em duas sessões realizadas no dia 12 de junho de 2018, com a presença de representantes do BID, da CAIXA, do Ministério das Cidades e da Prefeitura Municipal do Natal. A primeira sessão teve como público alvo as instituições que se relacionam, de alguma forma, com a área de intervenção, enquanto a segunda sessão foi aberta à população em geral, buscando-se, apresentar e debater a proposta, bem como colher críticas e sugestões, antes da finalização do produto final a ser entregue pela equipe vencedora. 
O seminário teve a participação de representantes das diversas secretarias do Município, de algumas secretarias do Estado, da Companhia Docas do RN, do IPHAN, da Superintendência do Patrimônio da União (SPU) no RN, da CBTU, do Instituto de Arquitetos do Brasil (IAB), do Conselho de Arquitetura e Urbanismo (CAU) do RN, do CREA/RN, da Universidade Federal do Rio Grande do Norte, da Estácio FAL, do Centro Universitário Facex, da Universidade Potiguar, da Federação das Associações Comerciais do RN, do Conselho Municipal de Planejamento Urbano, do Conselho Municipal de Habitação de Interesse Social, entre outros. Após exposição por parte dos representantes do BID, Ministério das Cidades, Caixa Econômica Federal e SEMURB, o projeto vencedor Olhos da Ribeira foi exposto e pôde receber contribuições dos presentes com questionamentos e sugestões. Ficou clara a expectativa dos diversos participantes de que as ideias construídas desde a década de 1980 e complementadas pelas inovações dos projetos participantes do concurso, alcancem a concretização. Destacando a importância de começar por pequenas ações que possam se somar até a concretização dos projetos, dos sonhos, da recuperação, da revitalização e da reabilitação tão almejados para a Ribeira.

A expectativa se refaz, com uma nova onda de investimentos que dessa vez venham de forma mais consistente com a perspectiva de que nos trilhos da Ribeira as marcas do passado levem a caminhos para o futuro, buscando na Ribeira - foz da cidade - a cidade nascente, uma Ribeira conectada para que a população de Natal busque viver + Ribeira, voltando os seus olhos para o Rio Potengi e para o bairro da Ribeira, sendo também os olhos da Ribeira parte da identidade do potiguar.

\section{REFERÊNCIAS}

SECRETARIA MUNICIPAL DE MEIO AMBIENTE E URBANISMO (SEMURB). ReHabitar em Natal. Natal/RN: CAIXA ECONOMICA/PREFEITURA MUNIICIPAL DE NATAL/FRANCE COOPERATION: 2008

TINOCO, M. B. M.; BENTES SOBRINHA, M. D. P.; TRIGUEIRO, E. B. F. Plano de Reabilitação de áreas urbanas Centrais. Natal/RN:EDURN - Editora da UFRN, 2008

SOUZA E SILVA, M. F. P. Antigos processos e novas tendências da urbanização norte-americana contemporânea. Cadernos Metrópole., [S.I.], v. 16, n. 32, p. 365-390, dez. 2014. ISSN 2236-9996. Disponível em: <https://revistas.pucsp.br/index.php/metropole/article/view/16931>. $\quad$ Acesso $\quad$ em: $\quad 13 \quad$ jul. 2018. doi:http://dx.doi.org/10.1590/16931.

\section{NOTAS}

1 Extraído do texto: SOUZA E SILVA, M. F. P. Antigos processos e novas tendências da urbanização norte-americana contemporânea. Cadernos Metrópole., [S.I.], v. 16, n. 32, p. 365-390, dez. 2014. ISSN 2236-9996. Disponível em: <http://revistas.pucsp.br/index.php/metropole/article/view/16931>. Acesso em: 10 jul. 2018. doi:http://dx.doi.org/10.1590/16931.

${ }^{2}$ Evento realizado no período de 6 a 11 de agosto de 2017 no Instituto Metrópole Digital (IMD) da Universidade Federal do Rio Grande do Norte (UFRN)

NOTA DO EDITOR (*) O conteúdo do artigo e as imagens nele publicadas são de responsabilidade do(s) autor(es). 